\title{
ECOLOGICAL SOCIETY OF AMERICA
}

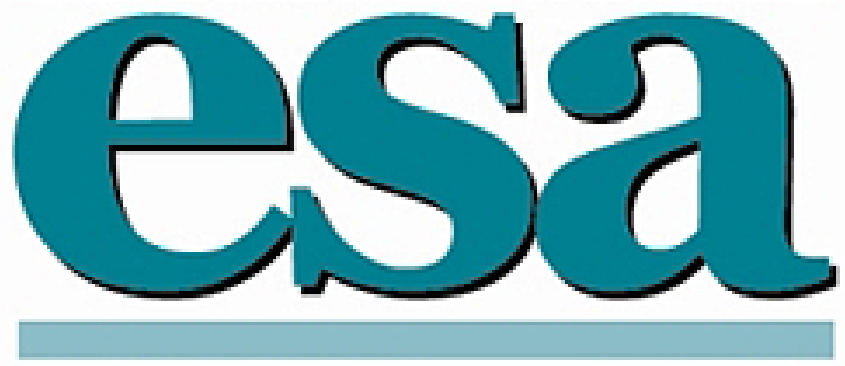

Conditional Mutualism in a Membracid-Ant Association: Temporal, Age-Specific, and DensityDependent Effects

Author(s): J. Hall Cushman and Thomas G. Whitham

Reviewed work(s):

Source: Ecology, Vol. 70, No. 4 (Aug., 1989), pp. 1040-1047

Published by: Ecological Society of America 


\title{
CONDITIONAL MUTUALISM IN A MEMBRACID-ANT \\ ASSOCIATION: TEMPORAL, AGE-SPECIFIC, AND DENSITY-DEPENDENT EFFECTS ${ }^{1}$
}

\author{
J. Hall Cushman ${ }^{2}$ and Thomas G. Whitham \\ Department of Biological Sciences, Northern Arizona University, Flagstaff, Arizona 86011 USA
}

\begin{abstract}
We examined the impact of a tending ant, Formica altipetens, on the population dynamics of a membracid, Publilia modesta. Controlled ant-exclusion experiments revealed three ways in which the strength and occurrence of this mutualism was conditional. First, we detected yearly variation in the impact of ants on membracids. Ants had a significant positive impact on membracid abundance in 1985 and 1987, but not in 1986 . Second, we found age-specific effects of ants on membracids. In 1985 and 1987 our experiments revealed that only membracid nymphs benefit directly from ant tending; we did not detect a direct positive impact of ants on the survival of membracid adults in any year. Third, we documented a density-dependent effect of ants on membracids. In 1985 and 1987 , nymphs in large aggregations benefited from ant tending more than nymphs in small aggregations.

Observations in 1985-1987 suggest that protection from a predatory salticid spider, Pellenes sp., may be at least one mechanism by which ants benefit membracid nymphs. In 1985 and 1987, when the association was mutualistic, spiders were significantly more abundant on membracid-infested plants without ants than on infested plants with ants, whereas this was not the case in 1986 . We hypothesize that the age-specific benefits in this system may result because nymphs are especially susceptible to predation by spiders whereas the more agile and sclerotized adults are not.

Key words: age-specific effects; ant tending; conditional mutualism; density dependence; Formica altipetens; Helenium hoopesii; membracids; Pellenes sp.; Publilia modesta; salticid spiders; temporal variation.
\end{abstract}

\section{INTRODUCTION}

Species interactions are strongly dependent on the physical and biological settings in which they occur (Wiens 1977, Boucher et al. 1982, Thompson 1982, 1988, Brown et al. 1986, Pulliam 1986). For example, Dunham (1980) found that two iguanid lizard species compete with each other in dry years but not in wet years. Brown (1971) documented that the outcome of competition between two chipmunk species depended on habitat type. The outcome of competition among prey species is frequently dependent on the density of predators (Paine 1966, Lubchenco 1978, Morin 1981, Freeland 1983). These and other recent studies illustrate that the occurrence, strength, and outcome of species interactions can be highly conditional.

Although numerous studies have documented the conditionality of competitive interactions, much less attention has been focused on mutualistic interactions.

\footnotetext{
' Manuscript received 8 April 1988; revised and accepted 3 September 1988.

${ }_{2}$ Present address: School of Biological Sciences, Macquarie University, Sydney, New South Wales 2109, Australia.
}

Mutualisms can be conditional in two ways. First, different mutualist species can vary in the quality of beneficial services that they provide to another species. For example, Schemske and Horwitz (1984) documented that floral visitors vary greatly in their ability to pollinate a neotropical herb. Bristow (1984) and Addicott (1979) have also shown that ant species vary in their ability to protect homopterans from natural enemies. In a similar study, Messina (1981) documented that ant species vary in their ability to protect homopteran host plants from a defoliating herbivore.

Second, the services provided by one mutualist species to another can vary with changes in the physical and biological setting. While this form of conditional mutualism has received less attention, there are a few examples in the literature. Dungan (1986) found that an intertidal limpet indirectly benefits barnacles only in the presence of an incrusting alga. Addicott (1979) suggested that a tending ant species benefits small aphid colonies more than large colonies. Fritz (1983) and Messina (1981) both predicted that the ability of ants to indirectly benefit homopteran host plants will depend on the density of other herbivores. McEvoy (1979) and Sudd (1983) found that the number of ants tending 
homopterans decreased as the distance from the servicing ants' nest increased (also see Laine and Niemela 1980).

In this paper, we focus on homopteran-ant associations, a common mutualism found throughout temperate and tropical regions. In such associations, ant species harvest the sugary waste excretions ("honeydew") of phloem-feeding homopterans. In return, tending ants provide a range of beneficial services to homopterans, the most frequently cited being protection from natural enemies (Nixon 1951, Way 1963, Sudd 1967, Carroll and Janzen 1973, Beattie 1985, Buckley 1987).

Here we consider how the dynamics of a homopteran-ant mutualism vary with time, age of homopterans, and size of homopteran aggregations. We present results from a 3-yr study that document that the occurrence and strength of this mutualistic interaction is strongly conditional.

\section{Study site and species}

The study was conducted at Fern Mountain Ranch (2700 m elevation), $\approx 40 \mathrm{~km}$ northwest of Flagstaff, Coconino County, Arizona. The study area, located in Hart Prairie on the western slope of the San Francisco Peaks, is dominated by low-growing herbaceous vegetation, particularly grasses.

Publilia modesta (Membracidae) is a sexually reproducing and univoltine homopteran found throughout the western United States (Kopp and Yonke 1973). P. modesta is sexually dimorphic, with males being smaller and darker than females. In northern Arizona these herbivores feed on a wide range of herbaceous perennial composites and are most abundant on Helenium (= Dugaldia $)$ hoopesii. Adults overwinter in the leaf litter and emerge in the spring to mate. Overwintering males are short lived and rarely persist into June. Females lay 20-40 eggs into the leaves and stems of the host, and aggregations of nymphs begin to appear in late June. Nymphs are much less mobile than adults and normally complete their 25-40 d development period on the natal plant. Newly eclosed adults can be distinguished from overwintering adults, as they have less sclerotized exoskeletons.

At the Fern Mountain study site both membracid adults and nymphs are actively tended by four ant species: Crematogaster sp., Formica altipetens, F. occulta, and $F$. oreas. In this paper we consider only the most abundant ant, $F$. altipetens. This ant species tends $P$. modesta both day and night, from May to September. F. altipetens forms distinct mound nests as well as more cryptic nests under rocks and in clumps of grass. It frequently builds satellite nests at the base of plants that are heavily infested with membracids. Cushman et al. (1988) presented three lines of evidence suggesting that intraspecific competition has strongly influenced the spacing patterns of $F$. altipetens: nests of this species are uniformly dispersed, the degree of uniformity increases with nest density, and the distance separating neighboring ant nests increases as their combined sizes increase.

A major predator of membracids at our study area is a salticid spider, Pellenes sp. (=Habronattus sp.). This highly visual and generalist predator was frequently observed feeding on membracid nymphs but rarely on the more agile and sclerotized adults. During the course of this study we observed an average of one spider per five membracid-infested plants. No other natural enemies were commonly associated with $P$. modesta during this study.

\section{METHODS \\ Ant-exclusion experiments}

From 1985 to 1987 we studied the impact of tending ants on membracid populations using controlled antexclusion experiments. Each year we marked all membracid-infested Helenium hoopesii flower stalks in a 20 $\times 50 \mathrm{~m}$ study plot and randomly selected a subset of these infested plants that were separated from each other by at least $1 \mathrm{~m}$. We used 19 infested plants per treatment in 1985,18 per treatment in 1986 , and 9 per treatment in 1987. We randomly assigned each infested plant to control (ants present) and experimental (ants excluded) treatments. Ants were excluded by applying a band of Tanglefoot (Tanglefoot Company, Grand Rapids, Michigan, USA) to the base of experimental flower stalks. Barriers were checked every $3 \mathrm{~d}$ to ensure that they were successfully excluding ants. We clipped back the grasses immediately surrounding both experimental and control plants, thereby blocking the access of ants to infested study plants from surrounding vegetation. We also placed tape sleeves around the base of both experimental and control flower stalks to eliminate the possibility that Tanglefoot was affecting host plant quality. We censused membracid populations four to five times during each of the monthlong experiments, categorizing the insects as being nymphs, overwintering adults, or newly eclosed adults.

In all analyses of the ant-exclusion data we compared the number of membracids present through time on control plants with those on experimental plants. The data are presented and analyzed in three ways. First, we considered the impact of ants on the total number of membracids. Second, we analyzed the impact of ants on overwintering adults and nymphs separately. We excluded newly eclosed adults from the analysis of adult abundance because including them would have confounded the effect of ants on adults with the effect of ants on nymphs. Third, we evaluated the impact of ants on large vs. small aggregations of nymphs.

In all cases we performed repeated-measure analysis of variances (ANOVAs) on membracid abundance data using the BMDP-2V statistical package (Dixon et al. 1985). For the analyses of membracid nymphs and adults considered together and separately, we per- 
1985

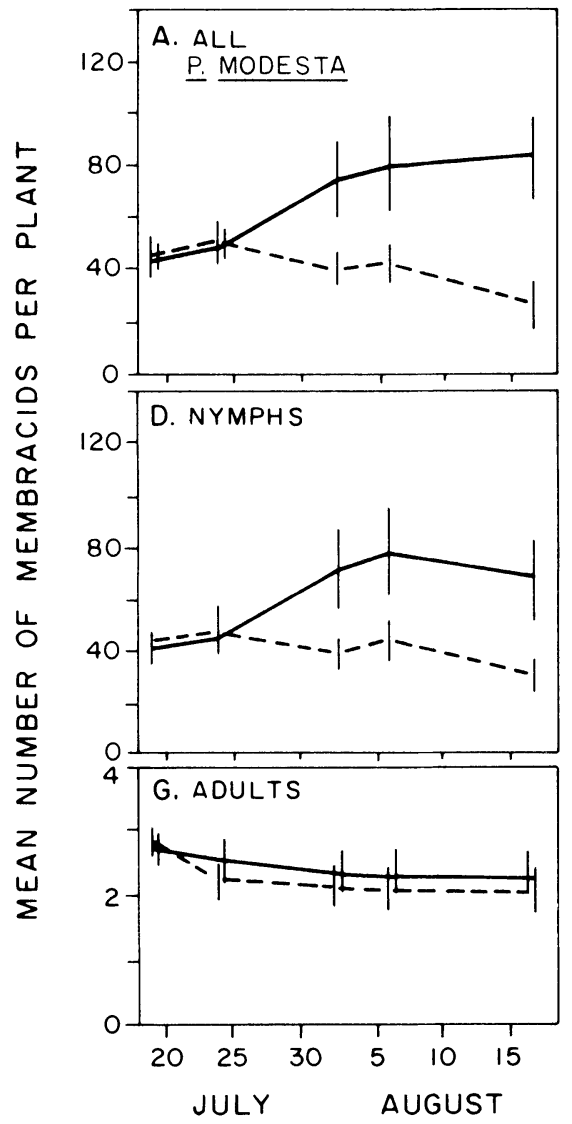

1986
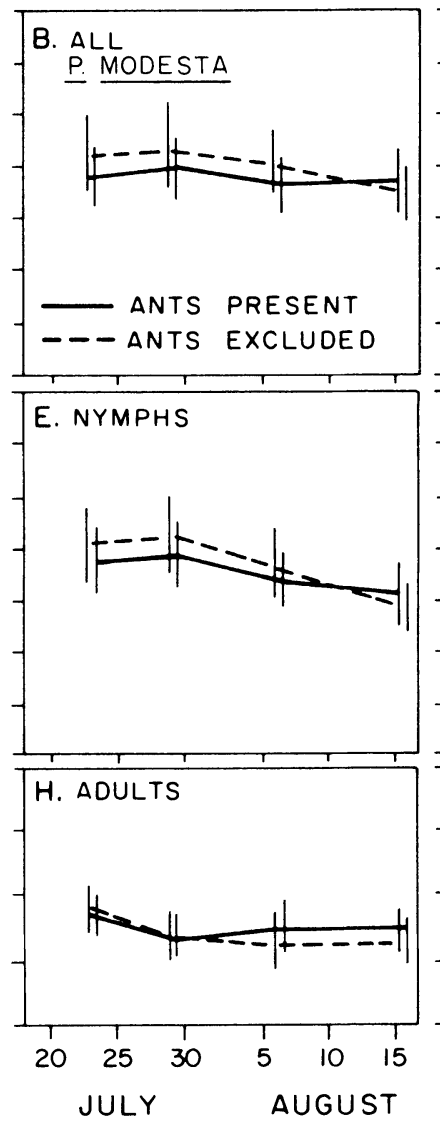

1987
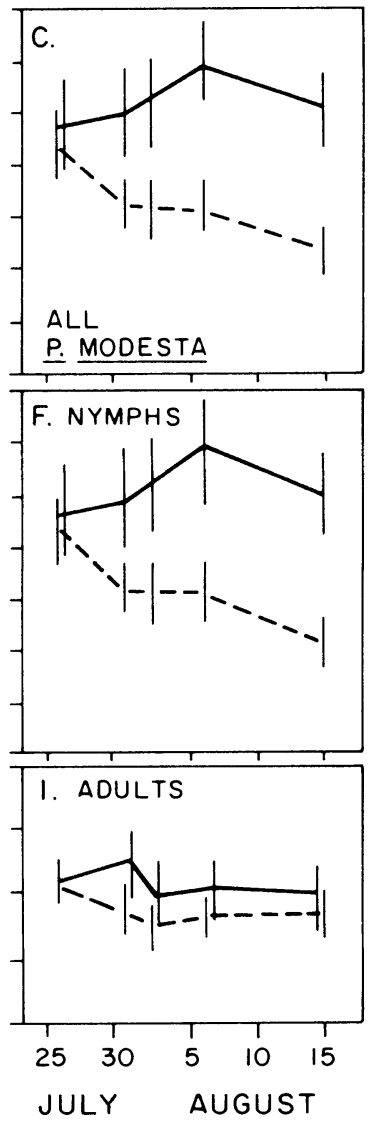

Fig. 1. The number of Publilia modesta per plant through time. — represents means for control plants (ants present); --- indicates means for experimental plants (ants excluded). Vertical bars illustrate \pm 1 SE.

formed one-way ANOVAs, with ant treatment (ants present or excluded) as the grouping factor and time as the repeated measure. For the aggregation-size analysis, we performed a two-way ANOVA with ant treatment and aggregation size (large or small) as the grouping factors and time as the repeated measure. Aggregations of nymphs were categorized as large or small before we applied the Tanglefoot barriers. In all three years those aggregations less than or equal to the initial median aggregation size were categorized as small and those greater than the median were categorized as large.

In the repeated-measure ANOVAs we present and discuss only grouping factor(s) $\times$ time interactions. For one-way ANOVAs we focus on the ant treatment $\times$ time interaction, and for two-way ANOVAs we discuss the ant treatment $\times$ aggregation size $\times$ time interaction. Discussion of the three main effects (ant treatment, time, and aggregation size) is not relevant to this study because (1) ant-treatment main effects are assessed by averaging across time, (2) time main effects are assessed by averaging across ant treatment, and (3) aggregation-size main effects are assessed by averaging across time and ant treatment. When interaction terms are present, this averaging makes it difficult to interpret the main effects (see Winer [1971] or Snedecor and Cochran [1980] for additional discussion).

\section{Salticid spider abundance}

Throughout each of the ant-exclusion experiments we noted the number of salticid spiders present through time on membracid-infested control and experimental plants. We performed square-root transformations on the data to stabilize treatment variances for the statistical analyses (we present untransformed data in Fig. 3 ). We performed one-way repeated-measure ANOVAs on the transformed spider-abundance data using the BMDP-2V statistical package, with ant treatment (ants present or excluded) as the grouping factor and time as the repeated measure.

\section{RESULTS}

\section{Ant-exclusion experiments}

In 1985 and 1987 the exclusion of ants resulted in a $54-68 \%$ decrease in the mean number of membracids 
TABLE 1. Repeated-measure ANOVAs performed on the number of Publilia modesta per plant; a, b, and c present two-way interactions between ant treatment and time for the indicated population group, while d gives three-way interactions among ant treatment, time and nymph aggregation size.

\begin{tabular}{|c|c|c|c|c|c|}
\hline $\begin{array}{l}\text { Year } \\
\text { Source }\end{array}$ & ss & df & MS & $F$ & $P$ \\
\hline \multicolumn{6}{|l|}{1985} \\
\hline a. All P. modesta & 23293.92 & 4 & 5823.48 & 7.65 & $<0.0001$ \\
\hline Error & 103493.51 & 136 & 760.98 & & \\
\hline b. Adults & 0.77 & 4 & 0.19 & 0.56 & 0.6952 \\
\hline Error & 49.79 & 144 & 0.35 & & \\
\hline c. Nymphs & 14385.35 & 4 & 3596.34 & 5.20 & 0.0006 \\
\hline Error & 94033.38 & 136 & 691.42 & & \\
\hline d. Nymph aggregation size & 7847.18 & 4 & 1961.79 & 3.31 & 0.0128 \\
\hline Error & 75824.99 & 128 & 592.38 & & \\
\hline \multicolumn{6}{|l|}{1986} \\
\hline a. All P. modesta & 775.10 & 3 & 258.37 & 0.35 & 0.7900 \\
\hline Error & 62200.83 & 84 & 740.49 & & \\
\hline b. Adults & 0.66 & 3 & 0.22 & 1.21 & 0.3113 \\
\hline Error & 18.62 & 102 & 0.18 & & \\
\hline c. Nymphs & 824.49 & 3 & 274.83 & 0.33 & 0.8041 \\
\hline Error & 70097.93 & 84 & 834.50 & & \\
\hline d. Nymph aggregation size & 906.67 & 3 & 302.22 & 0.34 & 0.7937 \\
\hline Error & 68557.01 & 78 & 878.94 & & \\
\hline \multicolumn{6}{|l|}{1987} \\
\hline a. All $P$. modesta & 7184.96 & 4 & 1796.24 & 3.96 & 0.0092 \\
\hline Error & 31175.42 & 64 & 487.12 & & \\
\hline b. Adults & 1.96 & 4 & 0.49 & 1.20 & 0.3189 \\
\hline Error & 26.04 & 64 & 0.41 & & \\
\hline c. Nymphs & 7208.07 & 4 & 1802.02 & 3.74 & 0.0085 \\
\hline Error & 30813.56 & 64 & 481.46 & & \\
\hline d. Nymph aggregation size & 4734.07 & 4 & 1183.52 & 2.67 & 0.0414 \\
\hline Error & 24824.88 & 56 & 443.30 & & \\
\hline
\end{tabular}

on host plants through time (Fig. 1A, C; Table 1). We were unable to detect a positive impact of ants on membracids in 1986 (Fig. 1B; Table 1).

In both 1985 and 1987, the number of membracids on control plants increased significantly through time $(P<.0001$ for both years; Fig. $1 \mathrm{~A}, \mathrm{C})$. This increase was due to nymphs emerging from eggs embedded in stems and leaves of the host plant. Given that ant treatments were assigned randomly, we assumed that emergence of nymphs was also occurring on experimental plants, but similar increases were not observed due to the absence of ants.

In 1985 and 1987 the exclusion of ants resulted in a $55-57 \%$ decrease in the mean number of membracid nymphs on host plants through time (Fig. 1D, F; Table 1). In 1986 we were again unable to detect a treatment effect through time (Fig. 1E; Table 1). We did not detect a significant effect of ants on the abundance of overwintering adults in any year (Fig. $1 \mathrm{G}, \mathrm{H}$, and $\mathrm{I}$; Table $1)$.

We categorized membracid nymphs as being in large or small aggregations to determine whether the impact of ants on nymphs is density dependent. In 1985 and 1987 we detected a significant three-way interaction among ant treatment, aggregation size, and time (Fig. 2A, C; Table 1). In 1985 and 1987 the mean impact of tending ants was $36-46 \%$ greater for large aggrega- tions compared to small aggregations. As before, we did not detect such effects in 1986 (Fig. 2B; Table 1).

\section{Salticid spider abundance}

Protection from a predatory salticid spider may be at least one mechanism by which ants directly benefit membracid nymphs. In 1985 and 1987 spiders were, on average, $60-65 \%$ more abundant on membracidinfested plants when ants were excluded than when present (Fig. 3; Table 2). These were also the years in

TABLE 2. Repeated-measure ANOVAs performed on the number of salticid spiders (Pellenes sp.) per Publilia-infested control and experimental plant through time. Analyses were performed on square-root transformed data.

\begin{tabular}{lrrrrc}
\hline \hline $\begin{array}{l}\text { Year } \\
\text { Source }\end{array}$ & Ss & df & MS & $F$ & $P$ \\
\hline 1985 & & & & & \\
$\quad$ Ant treatment & 1.81 & 1 & 1.81 & 11.29 & 0.0019 \\
$\quad$ Error & 5.76 & 36 & 0.16 & & \\
1986 & & & & & \\
$\quad$ Ant treatment & 0.01 & 1 & 0.01 & 0.08 & 0.7752 \\
$\quad$ Error & 4.82 & 34 & 0.14 & & \\
1987 & & & & & \\
$\quad$ Ant treatment & 1.19 & 1 & 1.19 & 7.83 & 0.0129 \\
$\quad$ Error & 2.44 & 16 & 0.15 & & \\
\hline
\end{tabular}



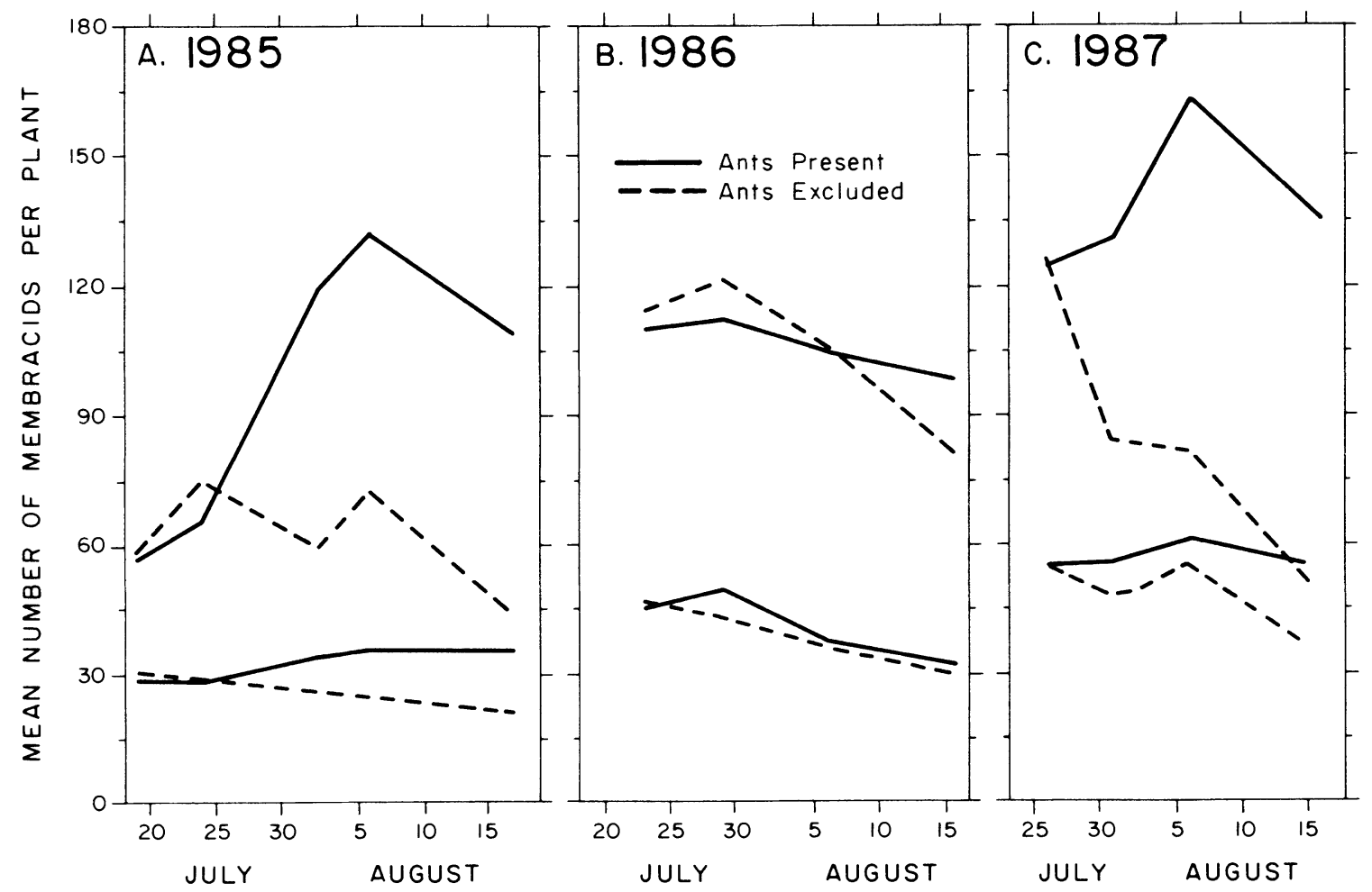

Fig. 2. The mean number of Publilia modesta nymphs per plant through time in large and small aggregations. represents large and small control aggregations (ants present); - - indicates large and small experimental aggregations (ants excluded).

which membracid nymphs acquired significant benefit from ant tending. In 1986, when nymphs did not benefit from tending, our data indicated that salticid spiders were less abundant than in 1985 and 1987 (by 28$34 \%$ ) and not influenced by the presence of ants.

\section{DisCussion}

Three years of experimental manipulations have shown that the interactions between $F$. altipetens and $P$. modesta are strongly conditional. First, while tending ants benefit membracids in most years, the mutualism does not occur in every year. Second, in those years when the association was mutualistic, closer inspection revealed that ants actually benefit only membracid nymphs and have no detectable direct impact on the survival of overwintering adults. Third, large aggregations of nymphs benefit more from ant tending than small aggregations. Fourth, we present observational data suggesting that this conditional mutualism may be, in part, driven by a predatory spider.

The abundance of salticid spiders suggests a potential mechanism for two of the conditional outcomes observed in this membracid-ant association. First, we detected a positive impact of ants on membracids only in those years when the presence of ants influenced the abundance of spiders (Figs. 1-3). This finding suggests that a major service provided to $P$. modesta by $F$. altipetens is protection from spider predators.

Second, our inability to detect a direct impact of ants on adult membracids is consistent with observations that adults have much greater mobility than nymphs and are rarely preyed upon by spiders. In addition, only adults possess a heavily sclerotized exoskeleton. Thus, perhaps nymphs require protection from spiders while adults are much less dependent on such services. Other investigators have previously suggested age-specific benefits in membracid-ant associations (McEvoy 1979, Wood 1982), but this is the first study to explicitly document its occurrence.

Density-dependent benefit to homopterans from ant tending has been suggested several times (Banks 1962, Banks and Macauley 1967, Addicott 1979, McEvoy 1979, Wood 1982). Addicott (1979) found that small colonies of the aphid Aphis varians acquired greater benefit from ant tending than large colonies. Banks (1962) and Banks and Macauley (1967) also observed that the ant Lasius niger provided greater benefit to small Aphis fabae colonies than to large colonies. Addicott (1979) suggested that such density dependence will occur when per-capita tending levels decrease with increasing aphid density. Addicott presents two mechanisms for how such a shortage of ants could result: 


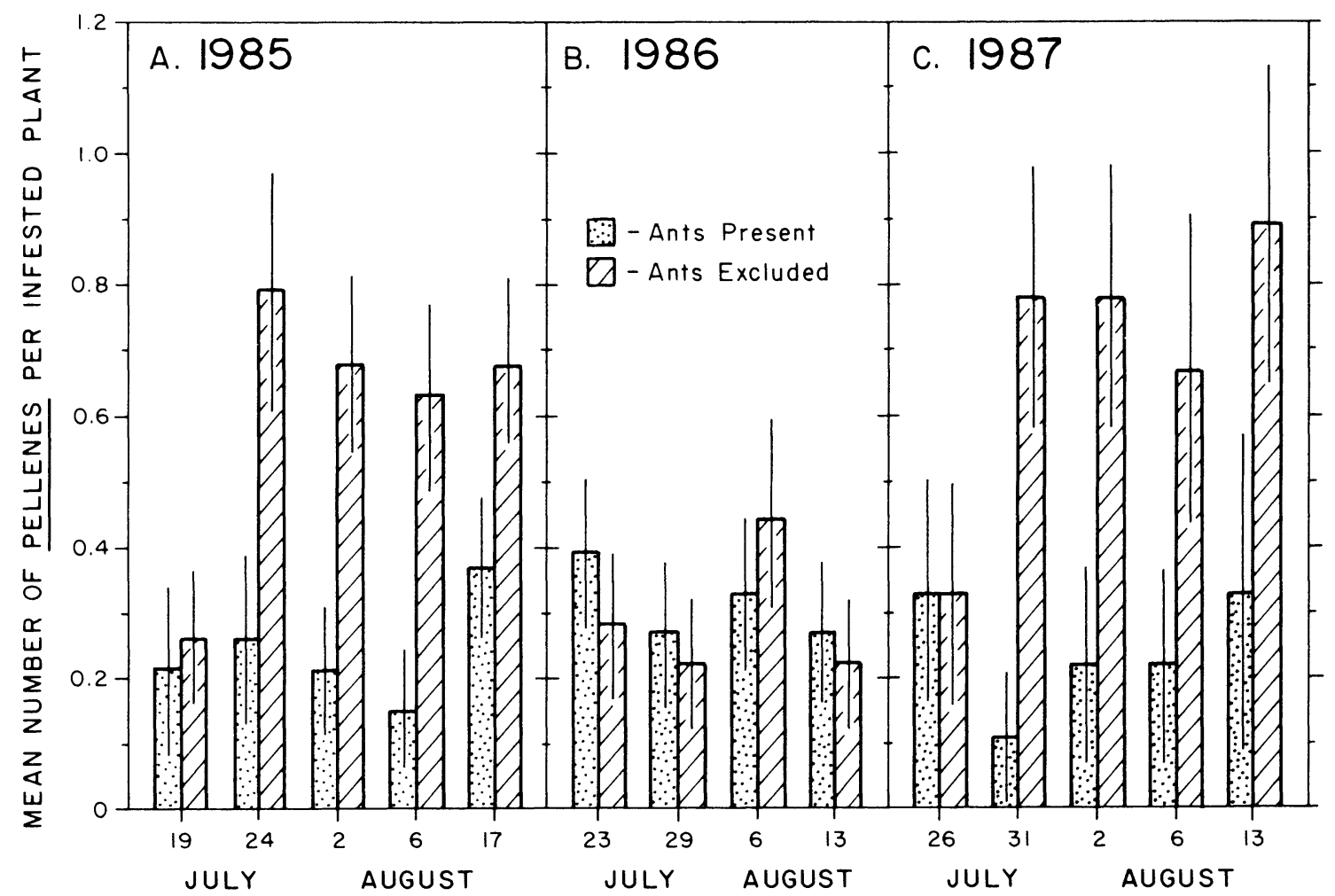

FIG. 3. The mean number of salticid spiders (Pellenes sp.) per membracid-infested control and experimental plant through time. Vertical bars illustrate $\pm 1 \mathrm{SE}$.

(1) ants may have a limited dietary requirement for honeydew which is met by small aphid colonies, and/ or (2) ants may be unable to respond numerically to the often exponential growth of aphid colonies.

Our experiments with the membracid $P$. modesta document the occurrence of positive density dependence rather than the negative density dependence reported by Addicott (1979) and others for aphids. With manipulative experiments in two years, we demonstrated that large membracid aggregations acquired 36$46 \%$ more benefit from ant tending than small aggregations.

The work of McEvoy (1979) on Publilia concava and Wood (1982) on the closely related Enchenopa binotata also provide evidence that large nymphal aggregations benefit more from ant tending than small aggregations. We suggest three possible mechanisms for how such positive density dependence could occur. First, larger aggregations produce more honeydew and thus may attract disproportionately more ants. For this to occur, per-capita tending levels would have to increase with aggregation size. While McEvoy (1979), Fritz (1982), Wood (1982), and others suggest or document positive correlations between homopteran aggregation size and the number of tending ants, we do not know of any studies showing that per-capita tending levels increase with aggregation size.
B. B. Edinger (personal communication) has provided a second potential explanation for why large homopteran aggregations might benefit more from ant tending than small aggregations. He demonstrated that ants (Campanotus noveboracensis) were more aggressive when tending large aphid colonies (Chaitophorus populicola) than small colonies. Thus, the increased aggression of ants towards natural enemies may explain why larger membracid aggregations benefit from ants more than small aggregations.

A third potential mechanism for positive density dependence involves variation in host plant quality. Large membracid aggregations may accumulate primarily on individual host plants that result in the production of (1) large quantities of honeydew and/or (2) honeydew that is rich in amino acids and sugars. If ants can detect these quantitative and qualitative differences, they may preferentially tend those membracids on "high-quality" hosts, or be more aggressive tenders. In support of this mechanism, numerous studies have shown that host plant quality strongly influences homopteran honeydew (see Auclair 1963) and that ants respond to changes in the composition and quantity of honeydew-like substances (Crawford and Rissing 1983, Lanza and Krauss 1984, Sudd and Sudd 1985; J. H. Cushman, personal observation).

Our results from three years of manipulative exper- 
iments reveal a complex and variable picture of a membracid-ant association. We assert that much of this variability is predictable and speculate that conditional mutualisms, such as the one discussed here, are not unusual. Our results suggest that the intensity and occurrence of species interactions are strongly dependent on the physical and biological setting in which they occur. Detection of such complexity illustrates the need for long-term studies that focus on the variability in species interactions and the resulting impact on natural communities.

\section{ACKNOWLEDGMENTS}

We thank John Addicott, Catherine Bristow, Alan Harvey, Frank Messina, Peter Price, Doug Schemske, and John Thompson for comments on drafts of this manuscript. We also thank Graydon Bell, Cal Berry, and Ralph Preszler for valuable discussion of repeated-measure analyses. Roy Snelling identified the ants, and Floyd Werner and Lloyd Knutson identified the membracid. This research has been supported by grants from NSF (BSR-8604983, BSR-8705347, and BSR8815544), USDA (GAM-8700709), Northern Arizona University, Sigma Xi, and the American Museum of Natural History. We thank the Wilson Foundation for permission to conduct research at Fern Mountain Ranch.

\section{Literature Cited}

Addicott, J. F. 1979. A multispecies aphid-ant association: density dependence and species-specific effects. Canadian Journal of Zoology 57:558-569.

Auclair. J. L. 1963. Aphid feeding and nutrition. Annual Review of Entomology 8:439-490.

Banks, C. J. 1962. Effects of the ant Lasius niger (L.) on insects preying on small populations of Aphis fabae Scop. on bean plants. Annals of Applied Biology 50:669-679.

Banks, C. J., and E. D. M. Macauley. 1967. Effects of Aphis fahae Scop. and of its attendant ants and insect predators on yields of field beans (Vicea faba L.). Annals of Applied Biology 60:445-453.

Beattie. A. J. 1985. The evolutionary ecology of ant-plant mutualisms. Cambridge University Press. London, England.

Boucher, D. H., S. James, and K. H. Keeler. 1982. The ecology of mutualism. Annual Review of Ecology and Systematics 13:315-347.

Bristow. C. M. 1984. Differential benefits from ant attendance to two species of Homoptera on New York ironwood Journal of Animal Ecology 53:715-726.

Brown, J. H. 1971. Mechanisms of competitive exclusion between two species of chipmunks (Eutamias). Ecology 52: 306-311.

Brown, J. H., D. W. Davidson, J. C. Munger, and R. S. Inouye. 1986. Experimental community ecology: the desert granivore system. Pages 41-62 in J. Diamond and T. J. Case, editors. Community ecology. Harper \& Row, New York, New York, USA.

Buckley, R. C. 1987. Ant-plant-homopteran interactions. Advances in Ecological Research 16:53-85.

Carroll, C. R., and D. H. Janzen. 1973. The ecology of foraging ants. Annual Review of Ecology and Systematics 4:231-257

Crawford. D. L.. and S. W. Rissing. 1983. Regulation of recruitment by individual scouts in Formica oreas Wheeler (Hymenoptera. Formicidae). Insectes Sociaux 30:177-183.

Cushman, J. H., G. D. Martinsen, and A. I. Mazeroll. 1988. Density-and size-dependent spacing of ant nests: evidence for intraspecific competition. Oecologia (Berlin) 77:522525.

Dixon, W. J., M. B. Brown, L. Engelman, J. W. Frane, M. A. Hill, R. I. Jennrich, and J. D. Toporek. 1985. BMDP statistical software. University of California Press, Berkeley, California, USA.

Dungan, M. L. 1986. Three-way interactions: barnacles, limpets, and algae in a Sonoran Desert rocky intertidal. American Naturalist 127:292-316.

Dunham, A. E. 1980. An experimental study of interspecific competition between the iguanid lizards Sceloporus merriami and Urosaurus ornatus. Ecological Monographs 50: 309-330.

Freeland, W. J. 1983. Parasites and the coexistence of animal host species. American Naturalist 121:223-236.

Fritz, R. S. 1982. An ant-treehopper mutualism: effects of Formica subsericea on the survival of Vanduzea arguata. Ecological Entomology 7:267-276.

1983. Ant protection of a host plant's defoliator: consequence of an ant-membracid mutualism. Ecology 64: 789-797.

Kopp, D. D., and T. R. Yonke. 1973. The treehoppers of Missouri: part 2. Subfamily Smiliinae; tribes Acutalini, Ceresini, and Polyglyptini. Journal of the Kanas Entomological Society 46:233-276.

Laine, K. J., and P. Niemela. 1980. The influence of ants on the survival of mountain birches during an Oporinia autumnata (Lep., Geometridae) outbreak. Oecologia (Berlin) 47:39-42.

$\rightarrow$ Lanza, J.. and B. R. Krauss. 1984. Detection of amino acids in artificial nectars by two tropical ants, Leptothorax and Monomorium. Oecologia (Berlin) 63:423-425.

Lubchenco, J. 1978. Plant species diversity in a marine intertidal community: importance of herbivore food preference and algal competitive abilities. American Naturalist 112:23-39.

McEvoy, P. B. 1979. Advantages and disadvantages to group living in treehoppers (Homoptera: Membracidae). Miscellaneous Publications of the Entomological Society of America 11:1-13.

Messina, F. J. 1981. Plant protection as a consequence of an ant-membracid mutualism: interactions on goldenrod (Solidago sp.). Ecology 62:1433-1440.

Morin, P. J. 1981. Predatory salamanders reverse the outcome of competition among three species of anuran tadpoles. Science 212:1284-1286.

Nixon. G. E. J. 1951. The association of ants with aphids and coccids. Commonwealth Institute of Entomology, London, England.

Paine. R. T. 1966. Food web complexity and species diversity. American Naturalist 100:65-76.

Pulliam. H. R. 1986. Niche expansion and contraction in a variable environment. American Zoologist 26:71-79.

Schemske. D. W., and C. C. Horwitz. 1984. Variation among floral visitors in pollination ability: a precondition for $\mathrm{mu}$ tualism specialization. Science 225:519-521.

Snedecor, G. W., and W. G. Cochran. 1980. Statistical Methods. Seventh Edition. Iowa State University Press, Ames, Iowa, USA.

Sudd. J. H. 1967. An introduction to the behaviour of ants. Edward Arnold Publishers, London, England.

1983. The distribution of foraging wood-ants (Formica lugubris Zett.) in relation to the distribution of aphids. Insectes Sociaux 30:298-307.

Sudd, J. H., and M. E. Sudd. 1985. Seasonal changes in the response of wood-ants to sucrose baits. Ecological Entomology 10:89-97.

Thompson, J. N. 1982. Interaction and coevolution. John Wiley \& Sons, New York, New York, USA.

- 1988. Variation in interspecific interactions. Annual Review of Ecology and Systematics 19:65-87. 
Way, M. J. 1963. Mutualism between ants and honeydewproducing Homoptera. Annual Review of Entomology. 8: 307-344.

Wiens, J. A. 1977. On competition in variable environments. American Scientist 65:590-597.

Winer. B. J. 1971. Statistical principles in experimental design. McGraw-Hill, New York. New York, USA.
Wood, T. K. 1982. Ant-attended nymphal aggregations in the Enchenopa binotata complex (Homoptera: Membracidae). Annals of the Entomological Society of America 75: 649-653.

\section{ERRATUM}

In an article by Kerry D. Woods and Margaret B. Davis ("Paleoecology of range limits: beech in the Upper Peninsula of Michigan," Ecology 70(3):681-696), the legend of Fig. 4 states that "Early Holocene shorelines for Lakes Michigan and Huron are shown by dashed lines." Because of a printer's error, these shorelines were omitted from the figure. Reproduced at the right are the maps for 8000,7500 , and $7000 \mathrm{yr} \mathrm{BP}$, with ancient shorelines included. By $6500 \mathrm{yr}$ BP shorelines stood at modern levels, so the remainder of Fig. 4 was correct as printed.

Also omitted from the article was the following acknowledgment: "The research reported in this paper has been supported by the U.S. National Science Foundation."

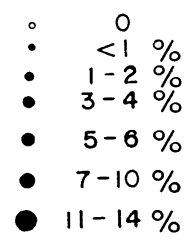

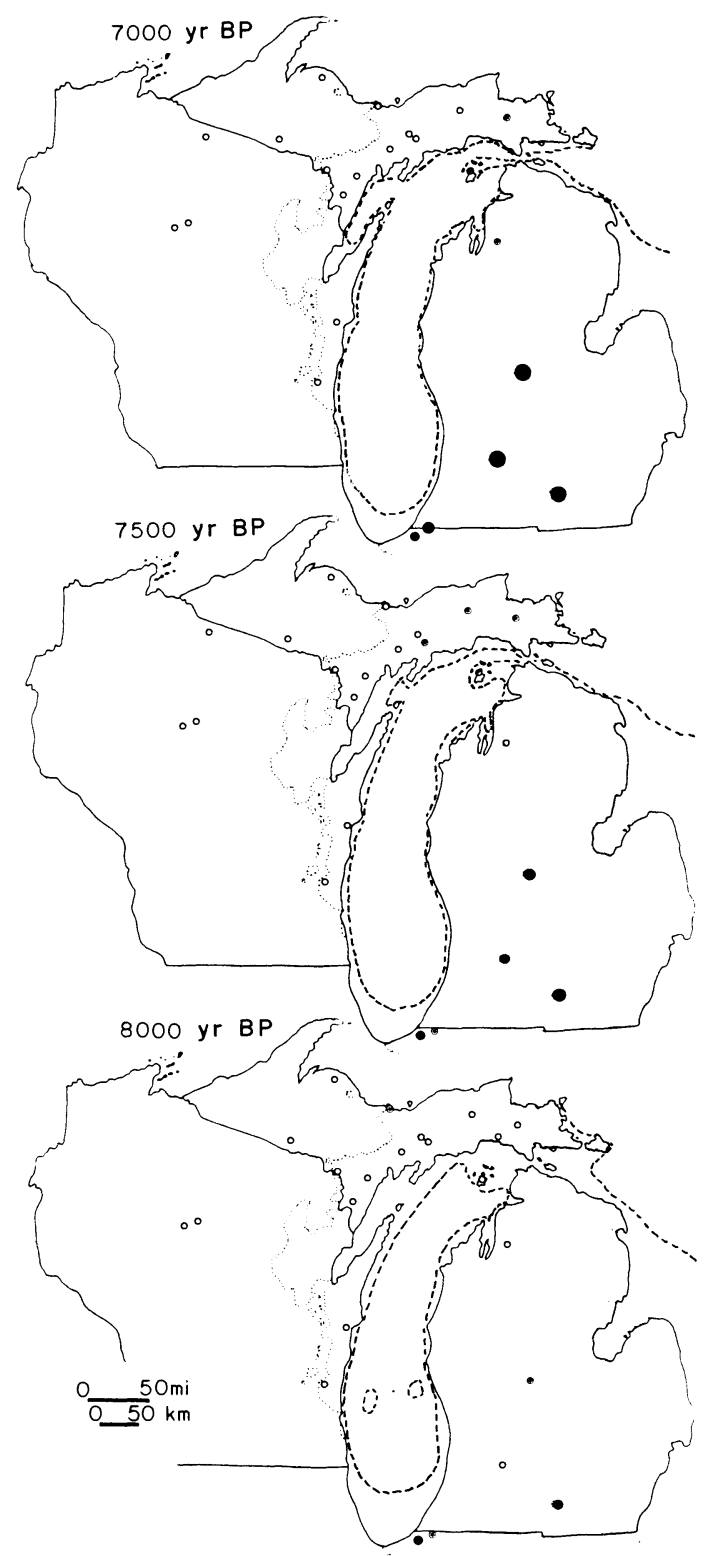

FIG. 4 (corrected). Maps showing beech pollen percentages at Michigan and Wisconsin sites at 500-yr intervals. Early Holocene shorelines for Lakes Michigan and Huron are shown by dashed lines. Shorelines have stood at modern levels since $6500 \mathrm{yr}$ BP. The remainder of Fig. 4 was correct as printed on pages 688-689 in Ecology 70(3). The figure legend on page 688 should be consulted for further information. 